Southern Illinois University Carbondale

OpenSIUC

Publications

Department of Geography and Environmental

Resources

9-30-2014

\title{
Assessing trends in lower tropospheric heat content in the central United States using equivalent temperature
}

Justin T. Schoof

Southern Illinois University Carbondale, jschoof@siu.edu

ZA Heern

MD Therrell

JWF Remo

Follow this and additional works at: http://opensiuc.lib.siu.edu/gers_pubs

\section{Recommended Citation}

Schoof, Justin T., Heern, ZA, Therrell, MD and Remo, JWF. "Assessing trends in lower tropospheric heat content in the central United States using equivalent temperature." International Journal of Climatology 35 (Sep 2014): 2828-2836. doi:10.1002/joc.4175.

This Article is brought to you for free and open access by the Department of Geography and Environmental Resources at OpenSIUC. It has been accepted for inclusion in Publications by an authorized administrator of OpenSIUC. For more information, please contact opensiuc@lib.siu.edu. 
1 This is the peer reviewed version of the following article:

2

3 Schoof JT, Heern ZA, Therrell MD, Remo JWF (2014) Assessing trends in lower tropospheric

4 heat content in the central United States using equivalent temperature. International Journal of

5 Climatology 35: 2828-2836.

6

7 which has been published in final form at

8 http://onlinelibrary.wiley.com/doi/10.1002/joc.4175/full

9

10 This article may be used for non-commercial purposes in accordance with Wiley Terms and

11 Conditions for Self-Archiving.

12

13 Final version accepted for publication in International Journal of Climatology on Aug. 29, 2014 14

15

16

17

18

19

20

21

22

23

24

25

26

27

28

29

30

31 
32 Assessing trends in lower tropospheric heat content in the Central USA using equivalent

33 temperature

34

35

J.T. Schoof*1 ${ }^{1}$ Z.A. Heern ${ }^{1}$, M.D. Therrell ${ }^{2}$, J.W.F. Remo ${ }^{1}$

36

$37{ }^{1}$ Department of Geography and Environmental Resources, Southern Illinois University,

38 Carbondale, IL, USA

$39 \quad{ }^{2}$ Department of Geography, University of Alabama, Tuscaloosa, AL, USA

40

41

42

43

44

45

46

47

48

49

50

Final version accepted by International Journal of Climatology

51

52

53

54

55

56

57

58

59

$60 *$ Corresponding author address: J.T. Schoof, Department of Geography and Environmental

61 Resources, Southern Illinois University, MC 4514, 1000 Faner Dr., Carbondale, IL 62901

62 E-mail: jschoof@ siu.edu, Tel: (618) 453-6019 


\section{Abstract}

64 Isobaric equivalent temperature $\left(T_{E}\right)$ is the temperature that an air parcel would have if all associated water vapor were condensed and the resulting latent heat used to increase the

66 temperature of the parcel. It is therefore an ideal metric for assessing changes in (1) total near

67 surface heat content associated with both temperature and moisture content and (2) the joint

68 behavior of temperature and humidity, which is relevant to both lower atmospheric stability and

69 human heat stress during extreme temperature events. We present results from an analysis of 50-

70 years (1961-2010) of daily $\mathrm{T}_{\mathrm{E}}$ and its temperature and moisture components at seven stations in

71 the central USA. The annual means of daily $\mathrm{T}_{\text {Emax }}$ and $\mathrm{T}_{\text {Emin }}$ increased at all stations during the

72 period of analysis with the largest changes occurring in $\mathrm{T}_{\text {Emin }}$, largely as a result of increasing

73 minimum air temperature. At western locations significant increases in the annual mean $\mathrm{T}_{\mathrm{Emax}}$

74 were also observed, resulting from a combination of increases in $\mathrm{T}_{\max }$ and humidity. Despite

75 small summer (JJA) trends in maximum air temperature, summer $\mathrm{T}_{\mathrm{E}}$ trends were generally larger

76 than their annual counterparts. The timing of the observed variations and the resulting spatial

77 pattern are consistent with observed changes in meridional moisture flux associated with the

78 Great Plains low-level jet. Heat waves in the region were found to be characterized by

79 increasing $\mathrm{T}_{\mathrm{Emin}}$, primarily resulting from increases in minimum air temperature. At western

80 stations, heat waves were also characterized by increasing $\mathrm{T}_{\mathrm{Emax}}$ as a result of positive trends in

81 humidity. In most cases, equivalent temperature provides a perspective on local environmental

82 change that differs from what is provided by consideration of temperature alone.

83

84

85

86

87

88

89

90 


\section{Introduction}

Variations and trends in lower tropospheric heat content are usually assessed using nearsurface air temperature data. However, this approach ignores variations in heat related to changes in moisture content and therefore provides an incomplete description of available energy near the surface (Pielke et al. 2004; Rogers et al. 2007). Pielke et al. (2004) recommend using moist static energy $(\mathrm{H})$ for this purpose. Moist static energy $(\mathrm{H})$ is given by:

$$
H=C_{p} T+L_{v} q
$$

where $C_{p}$ is the specific heat of air at constant pressure $\left(1005 \mathrm{~J} / \mathrm{kg}^{\circ} \mathrm{C}\right), \mathrm{T}$ is the air temperature $\left({ }^{\circ} \mathrm{C}\right), \mathrm{L}_{\mathrm{v}}$ is the latent heat of vaporization $(\mathrm{J} / \mathrm{kg})$ and $\mathrm{q}$ is the specific humidity $(\mathrm{kg} / \mathrm{kg})$. Division of $\mathrm{H}$ by $\mathrm{C}_{\mathrm{p}}$ yields equivalent temperature $\left(\mathrm{T}_{\mathrm{E}} ;{ }^{\circ} \mathrm{C}\right)$, which quantifies near surface heat content with separate terms for the dry and moist contributions:

$$
T_{E}=\frac{H}{C_{p}}=T+\frac{L_{v} q}{C_{p}}
$$

Globally, increases in humidity are well documented (e.g., Dai 2006) and further increases in lower-tropospheric water vapor are likely under future climate scenarios defined by increases in radiative forcing from greenhouse gases (Held and Soden 2006). This large scale response is likely to be regionally modified as a result of synoptic-scale moisture transport. For example, the Great Plains low-level jet (GPLLJ) - a feature characterized by strong lower tropospheric winds in the region between the Gulf of Mexico and the lee of the Rocky Mountains - is a key player in warm season hydroclimate variability in the central US (Weaver and Nigam 2011) and is an important factor in the moisture budget of the eastern US (Higgins et al. 1997). Locally, land cover is also likely to play an important role. Fall et al. (2010) found that trends in $\mathrm{T}_{\mathrm{E}}$, over the US, were larger than trends in $\mathrm{T}$ as a result of the moisture term (i.e., the $2^{\text {nd }}$ term in Equation 2) but with substantial influence from presence/absence of vegetation.

Since human heat stress is a function of both air temperature and atmospheric moisture content, there is also a need to assess changes in heat wave characteristics using metrics that account for changes in both temperature and humidity. The thermodynamic basis of equivalent temperature, as well as the clear separation of the dry and moist contributions to its magnitude, makes it an excellent choice for understanding such changes. In this study, we focus on a set of stations in the central United States (Figure 1) and use equivalent temperature to quantify several aspects of near surface equivalent temperature variability. The western part of the study region constitutes an area that has been referred to as "the warming hole" due to weak positive or near- 
125

126

127

128

129

130

131

132

133

134

135

136

137

138

139

140

141

142

143

144

145

146

147

148

149

150

151

152

153

154

155

zero trends in summer air temperature in recent decades, particularly in daily maximum air temperatures (Pan et al. 2004; Kunkel et al. 2006; Liang et al. 2006). Pan et al. (2004) attributed these trends to increases in precipitation associated with changes in the GPLLJ. In addition, some areas in the southeast US exhibit negative trends in annual mean near-surface air temperature that originate from internal decadal variability associated with Pacific sea-surface temperatures (Meehl et al. 2012). Including these areas in the study region therefore provides an opportunity to investigate changes in total heat content in a region where warming has been modest or even absent. Our primary objectives are to (1) assess trends in $\mathrm{T}_{\mathrm{E}}$ and its components and (2) determine the effect of these trends on the characteristics of regional heat waves.

The data used to address our objectives are described in Section 2, along with an assessment of data homogeneity. Section 3 includes a description of the methods employed in our analysis. The results are presented in Section 4, followed by a brief discussion in Section 5.

\section{Data}

Hourly values of temperature $(T)$, dew point temperature $\left(T_{d}\right)$, and station pressure $(P)$ were extracted for eight stations (Figure 1) from the National Oceanic and Atmospheric Administration (NOAA) Integrated Surface Database (ISD) available from the National Climatic Data Center (NCDC) along with available station metadata for the period of 1961-2010. The consistency of reports in the ISD varies considerably over the period of record. Observations are often reported hourly, but not at the same time within the hour. In these cases, observations were assigned to the nearest hour using traditional rounding principles. Furthermore, during the period from 1966-1981, values were only reported every three hours. To ensure consistency over the period of analysis, we partitioned each day into eight 3-hour blocks. For the daily $\mathrm{T}_{\mathrm{Emax}}$ and $\mathrm{T}_{\mathrm{Emin}}$ to be considered for further analysis, each 3-hour block had to have at least one hour with valid data.

Homogeneity of climate data is affected by factors ranging from station relocations and changes in instrumentation to changes in the surrounding environment, such as urbanization (Peterson et al. 1998; Changnon and Kunkel 2006), resulting in either discontinuities or gradual trends in the resulting time series (Easterling et al. 1996). Unfortunately, station location data for the early part of the record were kept with low precision making definitive distance calculations for station moves impossible. Nevertheless, the dates of station moves are available in the 
station history files available from NCDC, so time series can be objectively evaluated for associated discontinuities. Impacts from changes in sensors, specifically those related to implementation (1980s) and modification (early 1990s) of the HO-83 hygrothermometer have been addressed in several previous studies (Gall et al. 1992; Jones and Young 1995; Karl et al. 1995; Gaffen and Ross 1999; Robinson 2000). An additional change in dew point temperature measurement occurred with the installation of the Vaisala DTS1 dew point temperature sensor, which was installed at the stations considered here between 2003 and 2006.

Following Gaffen and Ross (1999) we conducted t-tests (with $\alpha=0.01$ ) using four years of monthly anomalies of maximum and minimum air temperature $\left(\mathrm{T}_{\max }, \mathrm{T}_{\min }\right)$ and dew point temperature $\left(\mathrm{Td}_{\max }, \mathrm{Td}_{\min }\right)$ before and after each documented station move and for the instrumentation changes that occurred in 1964, 1985, the mid-1990s (ASOS installation) and in the early 2000s (DTS1 installation). The implementation of ASOS and the installation of DTS are associated with specific dates in the station histories. The changes in the mid-1960s and mid1980s happened over a period of several years, so 1964 and 1985 are used as best estimates as in Gaffen and Ross (1999). In our examination of these differences, we considered whether any significant changes accompanied documented station changes, but also whether significant changes occurred simultaneously at neighboring stations where no changes in observation practices were noted.

During the 50-year period considered here, the seven stations in Figure 1 were moved a combined total of 20 times. Using the available location data as estimates, the station moves ranged from a few meters to $4.05 \mathrm{~km}$, but only one move was larger than $2 \mathrm{~km}$. The majority of the moves (13) were not associated with significant changes in any of the variables considered. Only one move (Moline, IL in 1992) was associated with a significant difference in temperature $\left(\mathrm{T}_{\max }\right)$. However, a significant change in $\mathrm{T}_{\max }$ in 1992 was also found at several other stations, suggesting that the difference was due to a true climatic influence rather than a station move. Similarly, changes in dew point temperature associated with six of the documented station moves were also coincident with significant changes (same direction, with $\alpha$ between 0.1 and 0.01 ) at nearby stations where moves were not documented. On the basis of this analysis, we concluded that documented station moves did not contribute to inhomogeneity in the station time series. The original time series were therefore subjected to further analyses corresponding to the dates of instrumentation changes. 
The instrumentation changes that occurred around 1964 resulted in only one significant change between preceding and following 4-year periods ( $\mathrm{T}_{\min }$ at Indianapolis). However, five of the six remaining stations also have a lower $\mathrm{T}_{\min }$ during the period from 1960-1963 relative to 1965-1968 (also significant at St. Louis with $\alpha=0.1$ ). The change to the HO-83 hygrothermometer in the mid-1980s has been associated with a warm bias in some environments (see Gall et al. 1992) and possibly a moist bias as well (Robinson 2000). Using 1985 as an approximate date for this change resulted in no significant changes in $T_{\max }$ or $T_{\min }$ at the stations considered here. A single station (St. Louis, MO) exhibits a significant difference in both maximum and minimum dew point temperature in 4-year periods surrounding 1985. However, St. Louis exhibits a decrease in dew point temperatures associated with this change. This outcome is opposite in sign to what would be expected from documented effects of the change to the HO-83 sensor.

Installation of the Automated Surface Observation System (ASOS) occurred in 1995 (3 stations), 1996 (3 stations) and 1999 (1 station) and included an upgrade to the HO-83 hygrothermometer designed to reduce warm bias. None of the stations exhibit a significant change in $\mathrm{T}_{\max }$ or $\mathrm{T}_{\min }$ associated with ASOS installation. A single station (St. Louis, MO), exhibited a significant change in both maximum and minimum dew point temperature.

However, this change was also observed at several other stations and therefore was unlikely to have resulted from the implementation of ASOS instrumentation. The installation of the DTS1 dew point temperature sensor was similarly associated with a significant change in maximum and minimum dew point temperature at St. Louis, MO, but again with similar changes at two other stations (Indianapolis, IN and Nashville, TN) that had no documented changes in instrumentation.

The analyses conducted using known and estimated changes in location and instrumentation did not identify any clear inhomogeneities in the station data, so no changes were made to the time series. However, non-climatic influences may also result from changes occurring in the environment around the stations, such as urbanization, changes in land use, or changes in agricultural practices. Existing station histories and ancillary data are inadequate to assess such changes. Without long-term records from reference stations, the first-order stations considered here provide the best long-term coincident temperature and dew-point temperature data available. 


\section{Methodology}

As shown in Eq. 2, computation of equivalent temperature requires specific humidity data. For each available station observation, the empirical relation of Bolton (1980) was first used to

222 derive vapor pressure (e) from the measured dew point temperature $\left(\mathrm{T}_{\mathrm{d}} ;{ }^{\circ} \mathrm{C}\right)$ :

$$
e=6.112 \exp \left(\frac{17.67 T_{d}}{T_{d}+243.5}\right)
$$

224 The vapor pressure and observed station pressure were then used to compute specific humidity $225(\mathrm{q} ; \mathrm{kg} / \mathrm{kg})$ :

$$
q=\frac{0.622 e}{P-0.378 e}
$$

227 Latent heat of vaporization $\left(\mathrm{L}_{\mathrm{v}}, \mathrm{J} / \mathrm{kg}\right)$, which also appears in Eq. 2, was computed as a function

228 229

230

231 of temperature $\left(\mathrm{T},{ }^{\circ} \mathrm{C}\right)$ following the Priestley-Taylor method as in Fall et al. (2010):

$$
L_{v}=2.5-0.0022 T
$$

Using these quantities, estimates of daily maximum and minimum equivalent temperature ( $T_{\mathrm{Emax}}$ and $\mathrm{T}_{\mathrm{Emin}}$ ) were computed.

Our analysis of changes in equivalent temperature and its components focused on two primary analyses. First a trend analysis was conducted to assess changes in equivalent temperature and its components at the stations in Figure 1. Trend analyses were conducted using median of pairwise slopes regression (MPWS; Lanzante 1996). MPWS is considered a robust regression technique and was used to minimize the impact of any unidentified inhomogeneities. In addition to annual and summer (JJA) trends, we conducted time-varying percentile trend analyses, similar to those of $\mathrm{T}_{\max }$ and $\mathrm{T}_{\min }$ conducted by Robeson (2004). In this approach, trends are computed for each calendar month and for the $5^{\text {th }}$ to $95^{\text {th }}$ percentiles leading to improved assessment of changes across the probability distributions.

A second analysis focuses on heat waves, defined here as multi-day periods in which $\mathrm{T}_{\max }$ exceeds its station-specific summer (JJA) $90^{\text {th }}$ percentile value. For each year, days associated with this criterion are identified and averaged to compute annual values of daily $\mathrm{T}_{\mathrm{Emax}}, \mathrm{T}_{\mathrm{Emin}}$, $\mathrm{T}_{\max }, \mathrm{T}_{\min }, \mathrm{L}_{\mathrm{v}} \mathrm{q} / \mathrm{C}_{\mathrm{Pmax}}$, and $\mathrm{L}_{\mathrm{v}} \mathrm{q} / \mathrm{C}_{\mathrm{Pmin}}$ associated with heat waves. The resulting averages are then subjected to a trend analysis to assess changes in the nature of heat waves in the context of equivalent temperature and its components. 


\section{Results}

\subsection{Annual and summer (JJA) trends}

Linear trends in the annual means of daily maximum and minimum air temperature $\left(\mathrm{T}_{\max }\right.$, $\mathrm{T}_{\min }$ ) are positive at each of the seven stations considered in this study (Table 1), consistent with the large-scale warming that occurred over the period considered (1961-2010). Trends in $\mathrm{T}_{\min }$ are highly significant (99\% level) at all stations and are generally larger than the trends in $\mathrm{T}_{\max }$ at the same station. A similar decrease in diurnal temperature range has also been observed at larger-scales (Karl et al. 1993; Easterling et al. 1997; Vose et al. 2005). Trends in $\mathrm{T}_{\max }$ are also significant at six of the seven stations. Annual values of the moisture component $\left(\mathrm{L}_{v} \mathrm{q} / \mathrm{C}_{\operatorname{Pmax}}\right.$, $\mathrm{L}_{v} \mathrm{q} / \mathrm{C}_{\text {Pmin }}$ ) exhibit positive trends at all stations except Nashville, although the trends are statistically significant at only a few stations (Table 1). These trends in temperature and atmospheric moisture are manifest as highly significant trends in the annual mean daily minimum equivalent temperature $\left(\mathrm{T}_{\text {Emin }}\right)$ at all stations. While all stations exhibit positive trends in both $\mathrm{T}_{\mathrm{Emin}}$ and $\mathrm{T}_{\mathrm{Emax}}$, the significance of $\mathrm{T}_{\mathrm{Emax}}$ trends is limited to stations with positive trends in both $\mathrm{T}_{\max }$ and $\mathrm{L}_{\mathrm{v}} \mathrm{q} / \mathrm{C}_{\mathrm{Pmax}}$.

Human health impacts of elevated temperature and humidity are most likely to occur during the summer months, so trends were also computed for summer (JJA) averages of daily $\mathrm{T}_{\mathrm{Emax}}$,

$265 \mathrm{~T}_{\mathrm{Emin}}, \mathrm{T}_{\max }, \mathrm{T}_{\min }, \mathrm{L}_{v} \mathrm{q} / \mathrm{C}_{\mathrm{Pmax}}$, and $\mathrm{L}_{v} \mathrm{q} / \mathrm{C}_{\mathrm{Pmin}}$ (Table 2). While the annual trends were characterized by warming in both $\mathrm{T}_{\max }$ and $\mathrm{T}_{\min }$, the JJA trends exhibit a notable lack of warming in $\mathrm{T}_{\max }$ at most stations, consistent with the "warming hole" described in section 1. Summer trends in $\mathrm{T}_{\min }$ are similar in magnitude and significance to their annual counterparts. With the exception of Nashville, all of the stations have positive trends in JJA averages of daily $\mathrm{L}_{\mathrm{v}} \mathrm{q} / \mathrm{C}_{\mathrm{Pmax}}$, and $\mathrm{L}_{\mathrm{v}} \mathrm{q} / \mathrm{C}_{\text {Pmin. }}$. These trends are significant at stations in the west/northwest part of the study region (Table 2). Trends in JJA average daily $\mathrm{T}_{\text {Emin }}$ are significant at the $95 \%$ level or higher and larger

272 in magnitude than their annual counterparts at all stations. The three stations exhibiting

273 significant trends in annual daily $\mathrm{T}_{\mathrm{Emax}}$ also exhibit significant trends in JJA daily $\mathrm{T}_{\text {Emax }}$.

\subsection{Percentile trends}

Trends in annual and JJA mean values of equivalent temperature and its components provide

278 focusing on change in the mean has the potential to mask important changes in other parts of the 
probability distribution. To investigate the nature of the changes presented in Tables 1 and 2, we computed trends for the monthly $5^{\text {th }}$ to $95^{\text {th }}$ percentiles of daily $T_{E \max }, T_{E \min }, \mathrm{T}_{\max }, \mathrm{T}_{\min }$, $\mathrm{L}_{\vee} \mathrm{q} / \mathrm{C}_{\mathrm{Pmax}}$, and $\mathrm{L}_{\mathrm{v}} \mathrm{q} / \mathrm{C}_{\mathrm{Pmin}}$. Examples of the resulting trends are presented for Des Moines, IA (Figure 2) and Indianapolis, IN (Figure 3), which are broadly reflective of the nature of the changes observed at the other stations in the western (Springfield, St. Louis, and Moline) and eastern (Memphis and Nashville) parts of the study region, respectively.

The trends in annual and JJA averages of daily $\mathrm{T}_{\max }$ and $\mathrm{T}_{\min }$ are positive at all of the stations considered here (Table 1, Table 2). While the overall magnitude of warming varies among the stations, several common features emerge from the analysis of percentile trends. At all of the stations, the largest positive temperature trends have occurred in the lowest percentiles of $T_{\max }$ and especially $\mathrm{T}_{\min }$ in the late winter and early spring (January-March). Each of the stations also exhibits trends of at least $2^{\circ} \mathrm{C}$ per 50 years in the lowest percentiles of $\mathrm{T}_{\min }$ during the summer months. At the northernmost stations (Des Moines and Moline, and to a lesser extent Indianapolis), increases in $\mathrm{T}_{\max }$ have occurred across the distribution during the spring months. Stations in the west and northwest exhibit small decreases in $\mathrm{T}_{\max }$, and in the upper percentiles of $\mathrm{T}_{\min }$, during the autumn months ( $\mathrm{SON}$ ), as well as decreases in the upper percentile values of $\mathrm{T}_{\max }$ during the summer.

The four westernmost stations (Des Moines, Springfield, Moline, and St. Louis) exhibit large trends $\left(>2^{\circ} \mathrm{C}\right.$ per 50 years) in both the maximum and minimum values of the equivalent temperature moisture term $\left(\mathrm{L}_{\mathrm{v}} \mathrm{q} / \mathrm{C}_{\mathrm{P}}\right)$ during August, followed by a decrease during the autumn months (Figure 2). At the eastern stations (Indianapolis, Memphis, and Nashville), summer increases in $\mathrm{L}_{\mathrm{v}} \mathrm{q} / \mathrm{C}_{\mathrm{P}}$ are smaller or absent, and fall decreases in $\mathrm{L}_{\mathrm{v}} \mathrm{q} / \mathrm{C}_{\mathrm{P}}$ are larger. The relative spatial coherence of the patterns in $\mathrm{L}_{\mathrm{v}} \mathrm{q} / \mathrm{C}_{\mathrm{P}}$ suggests that changes in large-scale circulation are involved. To investigate this possibility, we computed the average and trend in monthly $925 \mathrm{mb}$ meridional moisture transport ( $\mathrm{qv} ; \mathrm{gkg}^{-1} \mathrm{~ms}^{-1}$ ) in the NCEP-NCAR reanalysis over the same period used to compute the trends presented above. The $925 \mathrm{mb}$ level is used to capture moisture transport associated with the GPLLJ. The results, presented in Figure 4, indicate that July and August trends in moisture transport have been positive over the western stations, but that September trends are negative over the same region. These changes in large-scale moisture transport are consistent with the trends in $\mathrm{L}_{\mathrm{v}} \mathrm{q} / \mathrm{C}_{\mathrm{P}}$ observed at the stations. 
The percentile trends in temperature $\left(\mathrm{T}_{\max }, \mathrm{T}_{\min }\right)$ and moisture $\left(\mathrm{L}_{v} \mathrm{q} / \mathrm{C}_{\mathrm{Pmax}}, \mathrm{L}_{v} \mathrm{q} / \mathrm{C}_{P \min }\right)$ ultimately govern the percentile trends in equivalent temperature $\left(\mathrm{T}_{\mathrm{Emax}}, \mathrm{T}_{\mathrm{Emin}}\right)$. The largest trends in $\mathrm{T}_{\mathrm{E}}$ therefore occur when the sign of the trends in the temperature and moisture terms agree. The contribution from the moisture term sometimes leads to trends in $\mathrm{T}_{\mathrm{E}}$ that are opposite in sign to the temperature trend at the same station. As an example, the large positive trend in $\mathrm{L}_{\mathrm{v}} \mathrm{q} / \mathrm{C}_{\mathrm{Pmax}}$ during summer in Des Moines, IA leads to a positive trend in $\mathrm{T}_{\text {Emax }}$, despite small negative or small positive trends in $\mathrm{T}_{\max }$ (Figure 2). At stations where $\mathrm{T}_{\text {Emax }}$ increases during the summer, the change is largely due to changes in moisture. Changes in summer $\mathrm{T}_{\text {Emin }}$ tend to be larger because they result from changes in both the temperature and moisture terms. While the trends in both the temperature and moisture terms are positive during the winter, changes in $\mathrm{T}_{\mathrm{E}}$ are driven primarily by changes in air temperature.

\subsection{Analysis of heat waves}

Previous work has linked the human health impacts of extreme heat to multi-day events (e.g., Anderson and Bell 2011). While the annual, summer, and monthly percentile-specific trends provide insight into the distribution of equivalent temperature and its components individually, we are also interested in the interactions between temperature and humidity within the context of multi-day events. Here we focus on events of at least 2-days duration for which $\mathrm{T}_{\max }$ exceeds its station-specific summer (JJA) $90^{\text {th }}$ percentile value on each day. We then consider how the components of equivalent temperature have changed during such events over the period of analysis (1961-2010).

Our focus on multi-day events exceeding the $90^{\text {th }}$ percentile summer $T_{\max }$ value results in varying numbers of events identified for each station, ranging from an average of 1.9 events per year (Springfield) to 3.1 events per year (Indianapolis). Similarly, the number of total days meeting the heat-wave threshold varies from 354 days (1.9\%) at Springfield to 518 days (2.8\%) at Indianapolis (Table 3). Changes in $\mathrm{T}_{\max }$ during heat waves are small and are not statistically significant. All of the stations have experienced increases in $\mathrm{T}_{\min }$ during heat waves during the period of analysis, with the largest changes in Springfield, MO and St. Louis, MO (Table 3). These changes in $\mathrm{T}_{\max }$ and $\mathrm{T}_{\min }$ are broadly consistent with the summer trends observed at most stations (Fig. 2, Fig. 3, Table 2). Changes in moisture content associated with heat waves appears to be closely related to the trends in meridional moisture flux presented in Section 4.2, 
with increasing moisture content at western stations and decreasing moisture content at eastern stations. The four westernmost stations are characterized by significant increases in $\mathrm{L}_{v} \mathrm{q} / \mathrm{C}_{\operatorname{Pmax}}$ during heat waves. Des Moines, IA and Moline, IL are also characterized by significant increases in $\mathrm{L}_{\mathrm{v}} \mathrm{q} / \mathrm{C}_{\mathrm{Pmin}}$, while Nashville, $\mathrm{TN}$ is characterized by a significant decrease in $\mathrm{L}_{v} \mathrm{q} / \mathrm{C}_{\text {Pmin. }}$. Changes in equivalent temperature during heat waves are dependent on changes in both temperature and moisture. Two stations, Des Moines, IA and Moline, IL, exhibit significant increases in maximum equivalent temperature during heat waves as a result of increasing moisture content. The four westernmost stations have experienced significant changes in minimum equivalent temperature during heat waves, largely resulting from the combined effects of increases in $T_{\min }$ and $\mathrm{L}_{v} \mathrm{q} / \mathrm{C}_{\mathrm{Pmin}}$. None of the stations exhibit significant decreases in equivalent temperature during heat waves.

\section{Summary and discussion}

We have presented an analysis of changes in equivalent temperature and its components at seven stations in the Midwest USA for the period 1961-2010. Our results indicate that the annual mean of daily equivalent temperature has increased at all stations during this period, with the largest changes occurring (1) in minimum equivalent temperature at all stations and (2) in both maximum and minimum equivalent temperature at the westernmost stations. The former changes result from differential trends in $\mathrm{T}_{\min }$ and $\mathrm{T}_{\max }$, while the latter correspond with concurrent increases in temperature and atmospheric moisture content. During the summer (JJA), trends in $\mathrm{T}_{\max }$ are small (relative to their annual counterparts), but higher moisture content results in summer equivalent temperature trends that are generally larger than the annual trends, and statistically significant at the same stations.

Analysis of monthly percentile trends led to identification of several commonalities among the stations, including increases in the lowest percentiles of $\mathrm{T}_{\min }$ during the late winter and summer months, as well as a trend toward late-summer moistening followed by early fall drying. The latter situation appears to be related to changes in the meridional moisture flux associated with the GPLLJ. Recent studies have linked changes in GPLLJ intensity to several large-scale features, including the North Atlantic Oscillation (NAO) and North Atlantic subtropical high (Ruiz-Barradas and Nigam 2005; Patricola and Cook 2013), but also to variability related to the Pacific sector (Weaver and Nigam 2008; Patricola et al. 2013). Increases in mean maximum 
371 equivalent temperature during with winter months tend to be associated primarily with increases

372 in the temperature term, while those in the summer months tend to be associated primarily with

373 increases in the moisture term. Increases in mean minimum equivalent temperature result

374 primarily from increases in minimum air temperature that are strongest in the lowest percentiles

375 in the winter and summer. Increases in moisture during the summer at the westernmost stations

376 lead to large trends in minimum equivalent temperature.

377 Minimum temperatures during heat waves have increased at all of the stations. At all but the 378 two easternmost stations (Indianapolis and Nashville), heat waves are also characterized by 379 higher moisture content and therefore higher equivalent temperatures, especially at western 380 locations where the positive trend in the moisture term has been the largest. Changes in $\mathrm{T}_{\max }$ 381 have had little effect on heat wave conditions in the study area.

382 Our findings are subject to several caveats. First, existing station metadata are sufficient to conduct initial assessments of data homogeneity as we have done here, but insufficient to guarantee that the station time series are free of any non-climatic influences. Nevertheless, the data used here represent the best available data for addressing concurrent long-term trends in equivalent temperature and its components, and have also been used in other studies focused on assessing humidity trends (e.g., Gaffen and Ross 1999; Dai 2006). Furthermore, the general spatial coherence of the results suggests that the trends identified represent true climatic signals rather than non-climatic artifacts of urbanization or other changes within the station environment. Second, at large-scales humidity is largely a function of temperature. The breakdown of that relationship in the context of changing climate (i.e., the trends considered in this study), suggests that local humidity variations are also sensitive to processes occurring at smaller scales, such as regional moisture transport or even antecedent soil moisture conditions. Previous studies (e.g., Sandstrom et al. 2013) have described an association between increasing crop acreage and dew point temperatures. Future work will focus on assessing the relative roles of local processes and large-scale circulation changes in equivalent temperature variations in a larger station network.

Our findings suggest that reliance on temperature alone provides a misleading portrait of changes in near-surface energy content of air. A particularly noteworthy example is the increase in equivalent temperature during the summer months, and during heat waves, despite small changes or even decreases, in daily maximum air temperature. In this case, the lack of warming 
402 in $\mathrm{T}_{\max }$ masks changes in heat wave characteristics, such as increasing minimum temperature and

403 increasing humidity, which are important in the context of human health (e.g., Gaffen and Ross

404 1998). Recent work by Fischer and Knutti (2012) found that the uncertainty in CMIP5

405 projections of metrics combining temperature and humidity are smaller than they would be for

406 independent variables. We recommend that climate projection work focus on such combined

407 metrics for assessment of changes in near surface energy content and human health impacts of

408 rising temperatures.

409

410

\section{Acknowledgments}

411 This material is based upon work supported by the National Science Foundation under Grant No.

412 1339655. Any opinions, findings, and conclusions or recommendations expressed in this

413 material are those of the authors and do not necessarily reflect the views of the National Science

414 Foundation.

415

416

\section{References cited}

417 Anderson GB, Bell ML (2011) Heat waves in the United States: Mortality risk during heat waves 418 and effect modification by heat wave characteristics in 43 U.S. communities. Environmental 419 Health Perspectives 119, 210-218.

$421 \quad 1046-1053$.

422 Changnon SA, Kunkel KE (2006) Changes in instruments and sites affecting historical weather 423 records: a case study. Journal of Atmospheric and Oceanic Technology 23, 825-828.

Dai A (2006) Recent climatology, variability, and trends in global surface humidity. Journal of 425 Climate 19, 3589-3606.

426 Easterling DR, Peterson TC, Karl TR (1996) On the development and use of homogenized climate datasets. Journal of Climate 9, 1429-1434.

428 Easterling DR, Horton B, Jones PD, Peterson TC, Karl TR, Parker DE, Salinger MJ, Razuvayev

429 V, Plummer N, Jamason P, Folland CK (1997) Maximum and minimum temperature trends for the globe. Science 277, 364-367. 
Fall S, Diffenbaugh NS, Niyogi D, Pielke Sr RA, Rochon G (2010) Temperature and equivalent temperature over the United States (1979-2005). International Journal of Climatology 30, 2045-2054.

Fischer EM, Knutti R (2012) Robust projections of combined humidity and temperature extremes. Nature Climate Change 3, 126-130. DOI:10.1038/NCLIMATE1682.

Gaffen DJ, Ross RJ (1998) Increased summertime heat stress in the U.S. Nature 396, 529-530.

Gaffen DJ, Ross RJ (1999) Climatology and trends of U.S. surface humidity and temperature. Journal of Climate 12, 811-828.

Gall R, Young K, Schotland R, Schmitz (1992) The recent maximum temperature anomalies in Tucson: Are they real or an instrument problem? Journal of Climate 5, 657-665

Held IM, Soden BJ (2006) Robust responses of the hydrological cycle to global warming. Journal of Climate 19, 5686-5699.

Higgins RW, Yao Y, Yarosh ES, Janowiak JE, Mo KC (1997) Influence of the Great Plains lowlevel jet on summertime precipitation and moisture transport over the central United States. Journal of Climate 10, 481-507.

Jones CG, Young KC (1995) An investigation of temperature discontinuities introduced by the installation of the HO-83 thermometer. Journal of Climate 8, 1394-1402.

Karl TR, Jones PD, Knight RW, Kukla G, Plummer N, Razuvayev V, Gallo KP, Lindseay J, Charlson RJ, Peterson TC (1993) A new perspective on recent global warming: asymmetric trends of daily maximum and minimum temperature. Bulletin of the American Meteorological Society 74, 1007-1023.

Karl TR, Derr VE, Easterling DR, Folland CK, Hofmann DJ, Levitus S, Nicholls N, Parker DE, Withee GW (1995) Critical issues for long-term climate monitoring. Climatic Change 31, $185-221$.

Kunkel KE, Liang X-Z, Zhu J, Lin Y (2006) Can GCMs simulate the twentieth-century "warming hole" in the central United States? Journal of Climate 19, 4137-4153.

Lanzante JR (1996) Resistant, robust and nonparametric techniques for the analysis of climate data: theory and examples, including applications to historical radiosonde station data. International Journal of Climatology 16, 1197-1226. 
Liang X-Z, Pan J, Zhu J, Kunkel KE, Wang JXL, Dai A (2006) Regional climate model downscaling of the U.S. summer climate and future change. Journal of Geophysical Research-Atmospheres 111: DOI:10.1029/2005JD006685.

Meehl GA, Arblaster JM, Branstator G (2012) Mechanisms contributing to the warming hole and the consequent U.S. east-west differential of heat extremes. Journal of Climate 25, 63946408.

Pan Z, Arritt RW, Takle ES, Gutowski Jr. WJ, Anderson CJ, Segal M (2004) Altered hydrologic feedback in a warming climate introduces a "warming hole". Geophysical Research Letters 31, L17109, DOI:10.1029/2004GL020528.

Patricola CM, Cook KH (2013) Mid-twenty-first century climate change in the central United States. Part II: Climate change processes. Climate Dynamics 40, 569-583.

Patricola CM, Chang P, Saravanan R (2013) Impact of Atlantic SSTs and high frequency atmospheric variability on the 1993 and 2008 Midwest floods: Regional climate model simulations of extreme climate events. Climatic Change, doi: 10.1007/s10584-013-0886-1.

Peterson TC, Easterling DR, Karl TR, Groisman P, Nicholls N, Plummer N, Torok S, Auer I, Boehm R, Gullett D, Vincent L, Heino R, Tuomenvirta H, Mestre O, Szentimrey T, Salinger J, Forland EJ, Hanssen-Bauer I, Alexandersson H, Jones P, Parker D (1998) Homogeneity adjustments of in-situ atmospheric climate data: a review. International Journal of Climatology 18, 1493-1517.

Pielke RA, Davey C, Morgan J (2004) Assessing "global warming” with surface heat content. $\operatorname{Eos} \mathbf{8 5}, 210-211$.

Robeson SM (2004) Trends in time-varying percentiles of daily minimum and maximum temperature over North America. Geophysical Research Letters 31, L04203, DOI:10.1029/2003GL019019.

Robinson PJ (2000) Temporal trends in United States dew point temperatures. International Journal of Climatology 20, 985-1002.

Rogers JC, Wang SH, Coleman JSM (2007) Evaluation of a long-term (1882-2005) equivalent temperature time series. Journal of Climate 20, 4476-4485.

Ruiz-Barradas A, Nigam S (2005) Warm season rainfall variability over the U.S. Great Plains in observations, NCEP and ERA-40 reanlayses, and NCAR and NASA atmospheric model simulations. Journal of Climate 18, 1808-1830. 
491 Sandstrom MA, Lauritsen RG, Changnon D (2013) A central-U.S. summer extreme dew-point 492 climatology (1949-2000), Physical Climatology 25, 191-207.

493 Vose RS, Easterling DR, Gleason B (2005) Maximum and minimum temperature trends for the 494 globe: An update through 2004. Geophysical Research Letters 32, L23822, 495 DOI:10.1029/2005GL024379.

496 Weaver SJ, Nigam S (2008) Variability of the Great Plains low-level jet: Large-scale circulation 497 context and hydroclimate impacts. Journal of Climate 21, 1532-1551.

498 Weaver SJ, Nigam S (2011) Recurrent supersynoptic evolution of the Great Plains low-level jet. $499 \quad$ Journal of Climate 24, 575-582.

500

501

502

503

504

505

506

507

508

509

510

511

512

513

514

515

516

517

518

519

520

521 
522 Table 1. Trends in annual averages of daily $T_{E \max }, T_{E \operatorname{Emin}}, T_{\max }, T_{\min }, L_{v} q / C_{P \max }$, and $L_{v} q / C_{P \min }$.

523 All values are expressed in units of ${ }^{\circ} \mathrm{C}$ per 50 years. Significance of trends is shown for $90 \%{ }^{*}$,

$52495 \%^{* *}$ and $99 \%^{* * *}$.

\begin{tabular}{|c|c|c|c|c|c|c|}
\hline Station & $\mathbf{T}_{\text {Emax }}$ & $\mathbf{T}_{\text {Emin }}$ & $\mathbf{T}_{\max }$ & $\mathbf{T}_{\min }$ & $\mathbf{L}_{\mathbf{v}} \mathbf{q} / \mathbf{C}_{\mathbf{p m a x}}$ & $\mathbf{L}_{\mathbf{v}} \mathbf{q} \mathbf{C}_{\mathbf{P m i n}}$ \\
\hline Des Moines & $2.5^{* * *}$ & $2.8^{* * *}$ & $1.3^{* * *}$ & $1.4^{* * *}$ & $1.4^{* *}$ & $0.6^{*}$ \\
\hline Moline & $1.6^{* *}$ & $1.9^{* *}$ & $1.3^{* * * *}$ & $1.1^{* * *}$ & $1.0^{*}$ & 0.4 \\
\hline Indianapolis & 0.8 & $2.6^{* * *}$ & $1.0^{* *}$ & $1.5^{* * *}$ & 0.4 & 0.2 \\
\hline Springfield & 1.3 & $2.5^{* * *}$ & 0.3 & $1.0^{* * *}$ & 0.9 & $0.7^{*}$ \\
\hline St. Louis & $2.0^{* * *}$ & $3.7^{* * *}$ & $1.3^{* * *}$ & $2.3^{* * *}$ & $1.0^{*}$ & 0.7 \\
\hline Memphis & 1.3 & $2.7^{* * *}$ & $1.2^{* * *}$ & $1.6^{* * *}$ & 0.5 & 0.0 \\
\hline Nashville & 0.0 & $1.5^{* * *}$ & $0.6^{* *}$ & $1.2^{* * *}$ & -0.6 & -0.6 \\
\hline
\end{tabular}

525

526

527

528

529

530

531

532

533

534

535

536

537

538

539

540

541

542

543 
544 Table 2. Trends in summer (JJA) averages of daily $\mathrm{T}_{E \max }, \mathrm{T}_{\mathrm{Emin}}, \mathrm{T}_{\max }, \mathrm{T}_{\min }, \mathrm{L}_{\mathrm{v}} \mathrm{q} / \mathrm{C}_{\mathrm{Pmax}}$, and $545 \mathrm{~L}_{\mathrm{v}} \mathrm{q} / \mathrm{C}_{\text {Pmin. }}$. All values are expressed in units of ${ }^{\circ} \mathrm{C}$ per 50 years. Significance of trends is shown 546 for $90 \%^{*}, 95 \%^{* *}$ and $99 \%^{* * *}$.

\begin{tabular}{|c|c|c|c|c|c|c|}
\hline Station & $\mathbf{T}_{\mathbf{E m a x}}$ & $\mathbf{T}_{\mathbf{E m i n}}$ & $\mathbf{T}_{\max }$ & $\mathbf{T}_{\mathbf{m i n}}$ & $\mathbf{L}_{\mathbf{v}} \mathbf{q} / \mathbf{C}_{\mathbf{p m a x}}$ & $\mathbf{L}_{\mathbf{v}} \mathbf{q} \mathbf{C}_{\mathbf{P m i n}}$ \\
\hline Des Moines & $2.8^{*}$ & $3.8^{* * *}$ & 0.1 & $1.2^{* *}$ & $2.8^{* * * *}$ & $1.9^{* *}$ \\
\hline Moline & $1.7^{*}$ & $2.9^{* * * *}$ & 0.0 & $0.9^{*}$ & $1.8^{* *}$ & 1.2 \\
\hline Indianapolis & 0.2 & $3.3^{* * *}$ & 0.2 & $1.3^{* * *}$ & 0.4 & 0.7 \\
\hline Springfield & 1.3 & $4.7^{* * *}$ & 0.4 & $1.6^{* * *}$ & $1.9^{*}$ & $2.0^{* *}$ \\
\hline St. Louis & $2.8^{* *}$ & $5.1^{* * * *}$ & $1.0^{*}$ & $2.5^{* * *}$ & $1.9^{*}$ & 1.6 \\
\hline Memphis & 0.9 & $3.0^{* * *}$ & $1.6^{* * *}$ & $1.6^{* * *}$ & 0.7 & 0.0 \\
\hline Nashville & -0.5 & $2.2^{* *}$ & 0.9 & $1.5^{* * *}$ & -0.3 & -0.5 \\
\hline
\end{tabular}

547

548

549

550

551

552

553

554

555

556

557

558

559

560

561

562

563

564

565 
Table 3. Trends in annual average values of daily $T_{E \max }, T_{E \min }, T_{\max }, T_{\min }, L_{v} q / C_{P \max }$, and

$568 \mathrm{~L}_{\mathrm{v}} \mathrm{q} / \mathrm{C}_{\text {Pmin }}$ associated with warm events, defined as multi-day periods with $\mathrm{T}_{\max }$ greater than the

569 station-specific $90^{\text {th }}$ percentile value. All values are expressed in units of ${ }^{\circ} \mathrm{C}$ per 50 years.

570 Significance of trends is shown for $90 \%^{*}, 95 \%^{* *}$ and $99 \%^{* * *}$. Also shown are the numerical

571 values of the $90^{\text {th }}$ percentile of $T_{\max }$, number of number of warm events meeting this threshold

$572\left(\mathrm{~N}_{\mathrm{H}}\right)$ and the total number of days associated with those events $\left(\mathrm{N}_{\text {Hday }}\right)$.

\begin{tabular}{|c|c|c|c|c|c|c|c|c|c|}
\hline Station & $\begin{array}{c}\mathbf{T}_{\max } \\
\mathbf{P}_{\mathbf{9 0}}\end{array}$ & $\mathbf{N}_{\mathbf{H}}$ & $\mathbf{N}_{\text {Hday }}$ & $\mathbf{T}_{\mathbf{E m a x}}$ & $\mathbf{T}_{\text {Emin }}$ & $\mathbf{T}_{\max }$ & $\mathbf{T}_{\min }$ & $\mathbf{L}_{\mathbf{v}} \mathbf{q} / \mathbf{C}_{\mathbf{p m a x}}$ & $\mathbf{L}_{\mathbf{v}} \mathbf{q} / \mathbf{C}_{\mathbf{P m i n}}$ \\
\hline Des Moines & 33.3 & 143 & 476 & $6.5^{* *}$ & $6.3^{* * *}$ & -0.2 & $1.4^{* *}$ & $6.7^{* * *}$ & $3.7^{* *}$ \\
\hline Moline & 33.3 & 140 & 459 & $6.5^{* *}$ & $6.1^{* * *}$ & 0.2 & 0.8 & $6.4^{* *}$ & $4.4^{*}$ \\
\hline Indianapolis & 32.2 & 157 & 518 & -1.0 & 2.6 & 0.3 & 0.8 & -0.9 & -0.2 \\
\hline Springfield & 35.0 & 95 & 354 & 3.7 & $7.7^{* * *}$ & -0.1 & $1.8^{* * *}$ & $5.1^{* *}$ & 2.3 \\
\hline St. Louis & 35.0 & 138 & 432 & 3.7 & $4.3^{* *}$ & -0.1 & $1.5^{* * *}$ & $3.7^{*}$ & 2.8 \\
\hline Memphis & 35.6 & 111 & 415 & -0.1 & 3.0 & 0.3 & 0.7 & 1.3 & -1.4 \\
\hline Nashville & 34.4 & 122 & 433 & -2.6 & 0.9 & -0.4 & $1.0^{*}$ & -1.4 & $-4.1^{* * *}$ \\
\hline
\end{tabular}

573

574

575

576

577

578

579

580

581

582

583

584

585

586

587

588 
589 Figure 1. Map of study area, showing the locations of the seven stations used in the analysis.

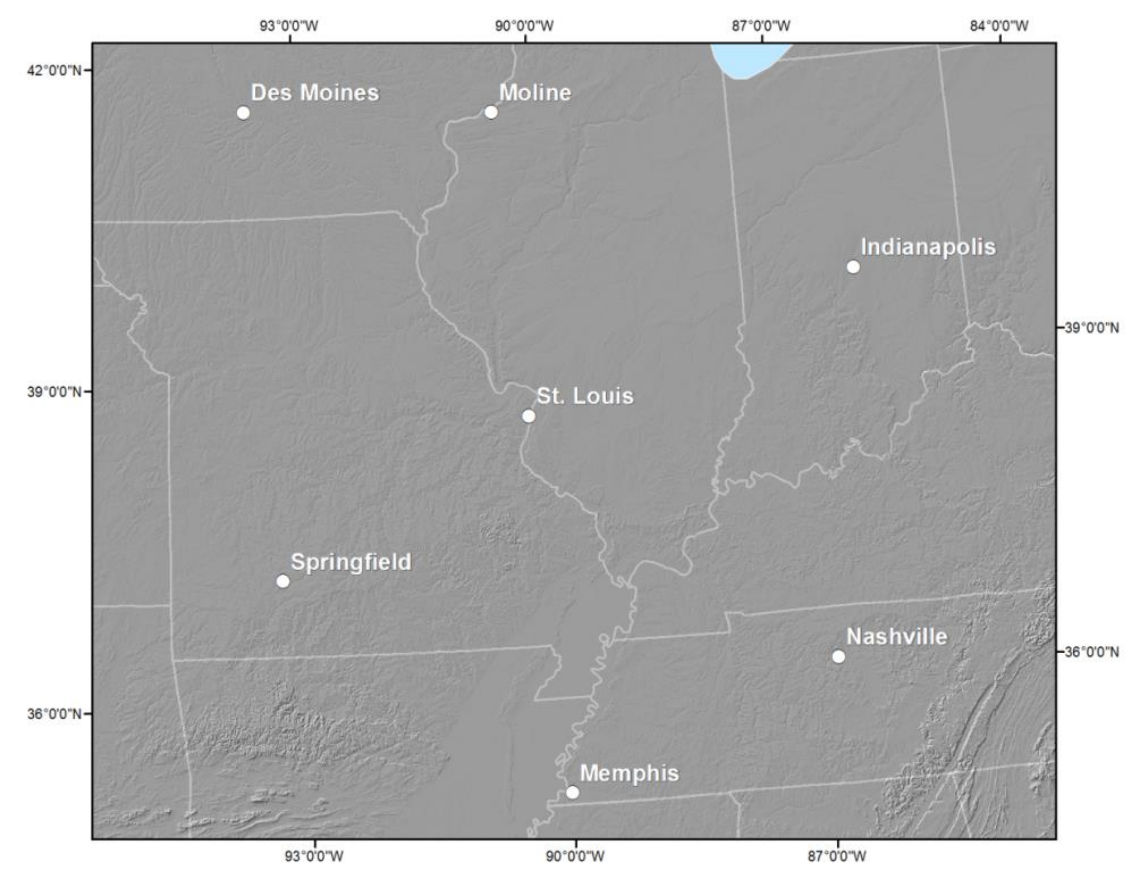

591 

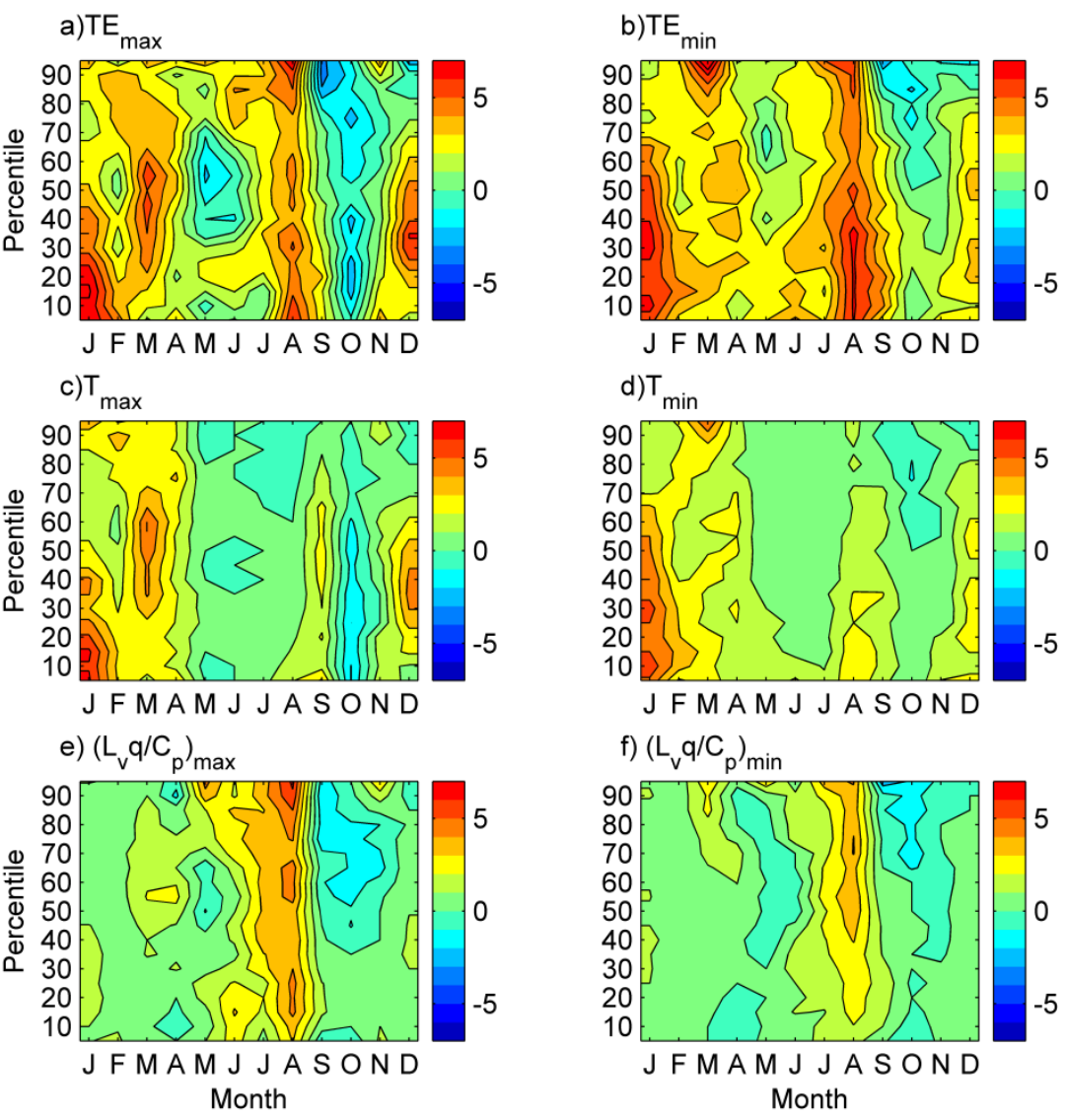

594 Figure 2. Monthly percentile trends for daily a) $\mathrm{T}_{E \max }$, b) $\mathrm{T}_{E \operatorname{Emin}}$, c) $\mathrm{T}_{\max }$, d) $\mathrm{T}_{\min }$, e) $\mathrm{L}_{\mathrm{v}} \mathrm{q} / \mathrm{C}_{P \max }$, 595 and $\mathrm{f}$ ) $\mathrm{L}_{v} \mathrm{q} / \mathrm{C}_{\mathrm{Pmin}}$ for Des Moines, IA. All values are expressed in units of ${ }^{\circ} \mathrm{C}$ per 50 years. The 596 trends presented for Des Moines are also broadly representative of changes at Sprinfield, MO, St. 597 Louis, MO and Moline, IL. 

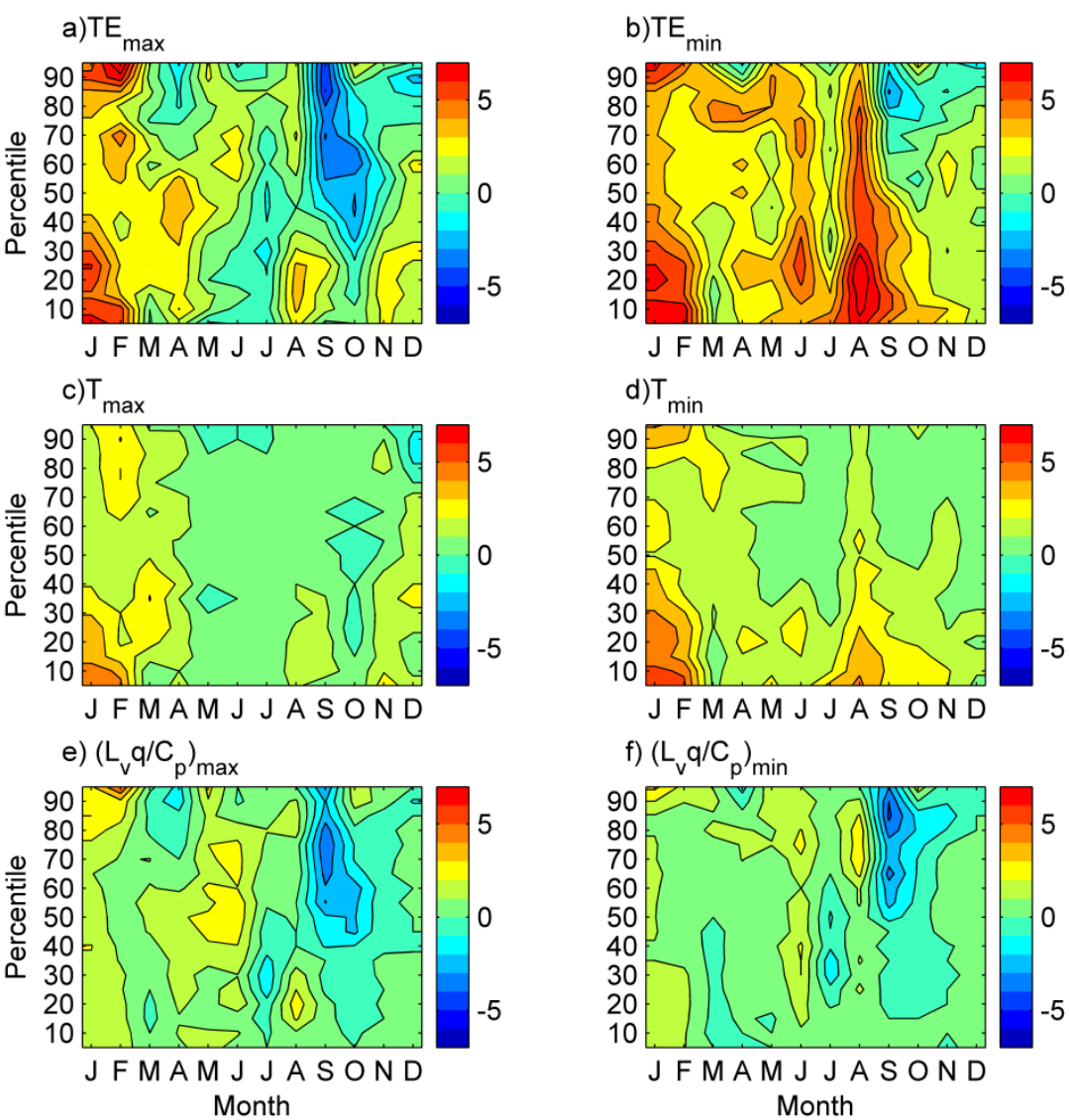

599 Figure 3. As in Figure 2, but for Indianapolis, IN. The trends presented for Indianapolis are also broadly representative of changes at Memphis, TN and Nashville, TN. 

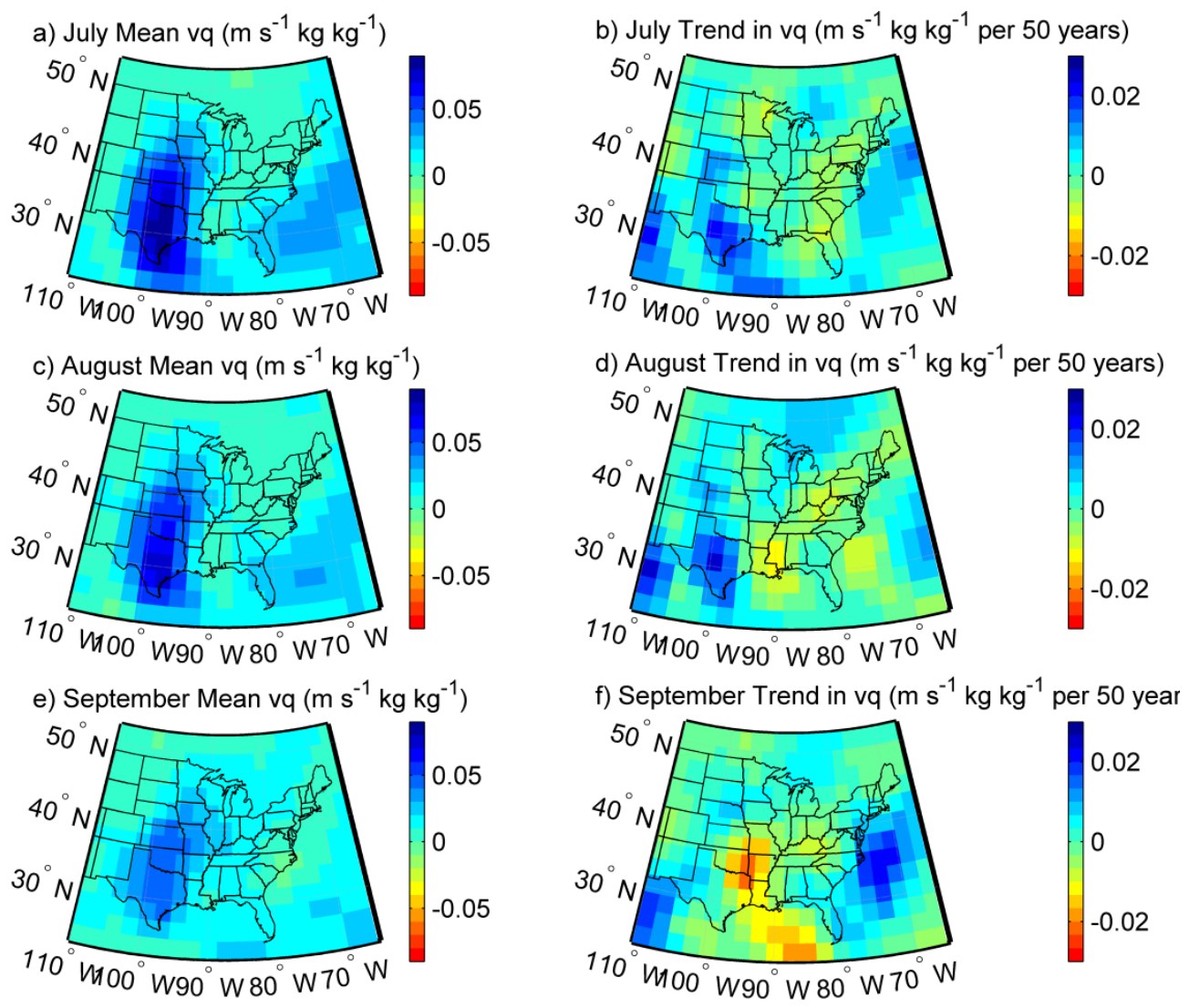

601

602 Figure 4. Average (left) and linear trend (right) in meridional moisture flux (vq) at $925 \mathrm{mb}^{\left(\mathrm{m} \mathrm{s}^{-1}\right.}$ $\left.603 \mathrm{~kg} \mathrm{~kg}^{-1}\right)$ for July (a,b), August (c,d), and September (e,f). 